\title{
La primera audición de las nueve sinfonías de Beethoven en México.
}

\author{
M.M. Fernando de Jesús Serrano Arias \\ Posgrado en Musicología UNAM* \\ Universidad de Sonora
}

Resumen

El año de 1910 no sólo convulsionó la situación política de México, el arte sinfónico, que venía desarrollándose paulatinamente desde fines del XIX, tuvo su primera función apoteósica; no sólo se estrenó la novena sinfonía de Beethoven, sino que, además, se interpretaron las ocho anteriores.

El presente trabajo aborda la temporada de otoño de la Orquesta del Conservatorio Nacional, dirigida por Carlos J. Meneses, la cual, teniendo como pretexto el centenario de la Independencia, presentó las nueve sinfonías de Beethoven por primera vez en nuestro país. A partir de la revisión de los periódicos capitalinos, se abordará la recepción de la época (críticas, reseñas, notas, anuncios, entre otros), tanto de las obras del "divino sordo", como de la interpretación de la orquesta.

\section{Hacia la novena}

"La popularización de Beethoven, el más genial de los compositores de todos los tiempos, intentada en los últimos conciertos por medio de las Sinfonías, tiene pues, amén del hieratismo casi religioso de un culto, la utilidad de una enseñanza". Así se refería, el 20 de noviembre de 1910 , Carlos González Peña en El Mundo Ilustrado a propósito de la finalizada temporada de conciertos de Carlos J. Meneses, al frente de la Orquesta del Conservatorio.

En el año de la celebración del centenario de la Independencia, siendo aún presidente Porfirio Díaz, se planificó todo un mes de actividades. El mes de septiembre se declaró festivo y como parte de esas festividades, se había pensado en la novena. Al menos eso parecía revelar el diario El País en una nota en donde lo indicaba, señalando incluso que, en el Conservatorio Nacional se preparaba la novena sinfonía de Beethoven. De ella, Gustavo E. Campa, su director, se expresaba diciendo que era "lo más grande que se ha producido en música, lo más maravilloso y lo más genial." También se hacia hincapié en la importancia y magnitud del evento que implicaba a los mejores solistas, una orquesta de entre ochenta y noventa músicos y un coro "de lo más coherente y disciplinado" para interpretar "la portentosa" obra del "genial Beethoven".

Para la prensa capitalina, era indudable la relevancia de tan importante evento. Diarios como El Correo Español, que por irónico que parezca celebraba nuestra independencia, a pesar de autodenominarse como un diario que estaba consagrado "a la defensa de los intereses de España y de la Colonia Española", imprimió que la ejecución de la novena "de aquel sublime sordo", era un anuncio celebrado en cualquier gran ciudad europea, por lo que no

\footnotetext{
1 "Tocarán la 9a sinfonía de Beethowen [sic]", El País, 9 de julio de 1910
}

*Esta investigación forma parte del trabajo de tesis desarrollado por quien esto escribe, como estudiante de doctorado en Musicología en la Universidad Nacional Autónoma de México. 
podía ser menos en la capital mexicana. Sin embargo, durante este acontecimiento no se presentó finalmente la novena sin darse mayores explicaciones en la prensa de la época. No obstante, el maestro Meneses decidió interpretar todas las sinfonías de Beethoven distribuidas en varios conciertos entre los meses de octubre y noviembre de 1910. Aunque no todas las sinfonías fueron primeras audiciones en nuestra capital.2 Como ya se sabe, fue en 1870 cuando Melesio Morales hizo escuchar por vez primera dos sinfonías de Beethoven a toda orquesta: la segunda sinfonía el 29 de diciembre de 1870 y la quinta sinfonía el 18 de enero de 1871.

Para el periódico El Diario, los conciertos organizados por Meneses iban dirigidos a un público culto e inteligente y la programación de las nueve sinfonías les permitiría a los amantes de la música orquestal, escuchar una de las obras de mayor expectación en el ámbito sinfónico.

Los conciertos se programaron semanalmente en lo que se llamaba regularmente "abonos". Estos se presentaban los jueves por la noche y los domingos por la tarde. Para tal efecto, se arrendó el teatro Arbeu $\mathrm{y}$, desde un principio se hizo del conocimiento del público que, salvo la novena, ninguna otra de las sinfonías se repetiría.

${ }^{2}$ Como ya se sabe, fue en 1870 cuando Melesio Morales hizo escuchar por vez primera dos sinfonías de Beethoven a toda orquesta: la segunda sinfonía el 29 de diciembre de 1870 y la quinta sinfonía el 18 de enero de 1871.
El Correo Español hacia el siguiente anuncio sobre la temporada de conciertos.

Va a ser un acontecimiento artístico la temporada de conciertos en el Teatro Arbeu. La Orquesta del Conservatorio, dirigida por Meneses, tiene ya una reputación de primer orden, ... Este año nos ofrece nada menos que las nueve sinfonías de Beethoven, es decir, el mundo inmenso de bellezas, pasiones, de amores que creó para sí aquel sublime sordo que, aislado del mundo exterior, falto de toda alegría y de todo placer, se recogió en sí mismo y en el fondo del alma formó un universo en el que hay triunfos, idilios, tempestades, amarguras, paisajes risueños, abismos, felicidades sin nombre. La novena sinfonía, cuyo anuncio es siempre celebrado en todas las grandes ciudades europeas, será interpretada por la Orquesta del Conservatorio con el aditamento de grandes masas corales. Oiremos, además, las obras maestras del Cristo de la música Wagner, de Saint-Saens, de Massenet... ${ }^{3}$.

Esto nos deja con un problema teológico musical. Si Wagner es el Cristo de la música ¿acaso será Beethoven su Dios?

\section{La temporada de conciertos}

Los conciertos vocales instrumentales que presentaba Meneses con la orquesta del Conservatorio mantuvieron un esquema similar toda la temporada. Divididos

3 "Los conciertos de Meneses en el Arbeu", El Correo Español, 08 de octubre de 1910.
Cuadro 1. Programa de los dos primeros conciertos de la serie.

\begin{tabular}{|c|c|c|c|c|c|}
\hline Programa & Autor & Secciones & Programa & Autor & Secciones \\
\hline $1^{a}$ Sinfonia & Beethoven & & $2^{a}$ Sinfonia & Beethoven & \\
\hline Tristán e Isolda & Wagner & $\begin{array}{l}\text { Muerte de amor de } \\
\text { Isolda }\end{array}$ & & & \\
\hline Sigfrido & Wagner & $\begin{array}{l}\text { Murmullos del } \\
\text { bosque; Canto del } \\
\text { Pájaro }\end{array}$ & Sigfrido & Wagner & $\begin{array}{l}\text { Murmullos del } \\
\text { bosque; Canto del } \\
\text { Pájaro }\end{array}$ \\
\hline $\begin{array}{l}\text { Concierto para } \\
\text { piano núm. I }\end{array}$ & Tchaikovski & & $\begin{array}{l}\text { Concierto para } \\
\text { piano núm. I }\end{array}$ & Tchaikovski & \\
\hline $\begin{array}{l}\text { La condenación } \\
\text { de Fausto }\end{array}$ & Berlioz & $\begin{array}{l}\text { Aria de Mefistófeles; } \\
\text { Sueño de Fausto }\end{array}$ & $\begin{array}{l}\text { La condenación } \\
\text { de Fausto }\end{array}$ & Berlioz & $\begin{array}{l}\text { Aria de Mefistófeles; } \\
\text { Sueño de Fausto }\end{array}$ \\
\hline Marcha Heroica & Saint Saens & & Marcha Heroica & Saint Saens & \\
\hline
\end{tabular}


en tres partes, iniciaba con una sinfonía de Beethoven, incluía obras operísticas, alguna otra obra sinfónica y, para el cierre, una obra orquestal de gran sonoridad.

El primero de ellos se llevó a cabo el 16 de octubre de 1910. Inició con la Primera Sinfonía seguida de "Muerte de amor de Isolda", "Murmullos del bosque" y "Canto del pájaro" de Wagner. En la segunda parte se escuchó el Concierto para piano núm. I de Tchaikovsky con Carlos Lozano como solista. En la tercera parte se interpretaron dos piezas de La condenación de Fausto de Berlioz: el "aria de Mefistófeles" y el "Sueño de Fausto" y concluyó con la Marcha heroica de Camille SaintSaens.

En el periódico El Diario, apareció una amplia crítica de la que presentamos el siguiente fragmento:

Con la infinita y plausible dedicación del maestro Meneses; con su meritoria labor de propalar el verdadero arte en México; con su incansable fuerza en la siembra de bellezas musicales, antier en la tarde principió la temporada de conciertos de la orquesta. La Primera Sinfonía del Supremo Sordo inauguró dignamente la audición vespertina, avasallándonos desde el primer tiempo hasta el Allegro molto vivace con que finaliza esa pura composición saturada de sublimes bellezas como el Minueto y el Adagio que nos embargan gratamente, con esa majestad sobria e inefable que es peculiar en las obras del inmortal sinfonista. ${ }^{4}$

El segundo concierto se realizó el jueves 20 de octubre por la noche teniendo como "portada", según declaraba El Imparcial, la "segunda sinfonía" de Beethoven y donde básicamente, se repitió, el programa del primer "abono". Lo único que se omitió fue "Muerte de amor" de Tristán e Isolda.

En El Correo Español, apareció la siguiente crítica:

${ }^{4}$ Castillo, José Luis del, "El concierto de anteayer en el Arbeu", El Diario, 18 de octubre de 1910
No había mucho público, pero estaba compuesto de esas personas de "elite" que en Méjico [sic], como en todas partes, acechan la ocasión de asistir a alguna de las manifestaciones sublimes del arte. Comenzó el concierto con la segunda sinfonía de Beethoven, prodigio de inspiración, de instrumentación, de arte divino. Beethoven se impone siempre y triunfa y reina sobre el trono del genio lo mismo hoy que ayer y lo mismo que triunfará mañana. Cada sinfonía, cada sonata de Beethoven es un mundo de afectos y de bellezas, el mundo interior que se creaba para sí aquel hombre sordo, infeliz, rodeado de un desierto triste e inacabable. ¿Qué emoción se experimenta al ser admitido en ese mundo! ¡Cómo el alma al conjuro de la música deja las pequeñeces y miserias de la vida y vuela por no sé que regiones de luz y de felicidad! La orquesta de Meneses tocó bastante bien todos los tiempos de la sinfonía, salvo algún pasaje de las trompas. ${ }^{5}$

Para el tercer concierto, presentado el 23 de octubre se inició, como es de suponer, con la Heroica. En esta ocasión, Meneses incluyó la "Tarantela" y la "Marcha" de la Sinfonía Patética de Tchaikovski y el "primer concierto para piano y orquesta" de Liszt con María Solórzano como solista. La parte operística estuvo a cargo del Parsifal de Wagner del que se interpretaron "El jardín encantado" y la "Seducción de las flores". Para concluir Meneses eligió de nuevo una obra de gran sonoridad, la Obertura 1812 de Tchaikovsky. Sobre las primeras sinfonías de Beethoven El Imparcial presentó una reseña escrita por una persona cuyo pseudónimo era " $\mathrm{Cu}$ rioso":

Y si la primera sinfonía de Beethoven está aún concebida bajo el imperio de Mozart, la segunda ha roto ya las cadenas de oro y abre, libremente, las alas. Es el grito de la 'emancipación'; no es todavía el de la 'revolución'; éste, sale, con sonoridad de clarín guerrero, de la "tercera sinfonía" en 'mi bemol', de la 'heroica' que retrata, mejor tal vez que ninguna otra obra, el carácter batallador, el anhelo de libertad,

${ }^{5}$ G.B., "El concierto de anoche en Arbeu", El Correo Español, 21 de octubre de 1910. 
que animaron a Luis Beethoven, al lector de Plutarco, al soñador de la república de Platón. ${ }^{6}$

El cuarto concierto, el 27 de octubre, inició con la cuarta sinfonía de Beethoven. La parte segunda presentó el Triple concierto para piano, violín y cello del mismo Beethoven con Carlos Lozano, Pedro Valdés Fraga y Horacio Ávila como solistas y, para concluir, repitieron tanto las obras de "Parsifal" como la "1812".

Para "Maese Pedro", el crítico del Semanario El Mundo Ilustrado, seudónimo de Carlos González Peña, declaraba después del concierto:

El triunfo, tan deseado, tan justo, empieza a coronar los esfuerzos del maestro $\mathrm{Me}$ neses y de los artistas que, dirigidos por él, vienen realizando desde hace algunas semanas esa admirable obra de cultura musical que significan los conciertos del 'Arbeu': el público acude ya en masas compactas, llena el teatro, emula con aplauso merecidísimo a los ejecutantes, y los programas son cada vez más trascendentales y altos. ${ }^{7}$

Y finalizaba escribiendo: "Implantar en México el culto de Beethoven y de Wagner, las dos más elevadas representaciones del arte musical, será, pues, el mejor remate que haya soñado el maestro Meneses para coronar su labor de tantos años"

El quinto concierto rompió parcialmente la estructura de los anteriores. Éste inició con la Sexta sinfonía a pesar de que el orden implicaba la presentación de la Quinta. De hecho, ésta no se ejecutó sino hasta a mediados de noviembre de ese año, cuando la temporada ya había concluido. Fue la noche del beneficio de la orquesta en la que sólo se interpretaron la 1812 y la Quinta sinfonía.

\footnotetext{
${ }^{6}$ Curioso, "Cartas al maestro Meneses. Impresiones sobre la temporada de conciertos", El Imparcial, 23 de octubre de 1910.

7 Maese Pedro, "Un triunfo del maestro Meneses", "Teatrales", El Mundo Ilustrado, 06 de noviembre de 1910

${ }^{8}$ Idem
}

En este programa se incluyó la Fantasía coral de Beethoven, con Carlos Lozano al piano; y el Himno a Víctor Hugo de Saint-Saens. La última sección inició con el Viaje de Sigfrido por el Rhin y finalizó con la Cabalgata de las Valkirias, ambas de Wagner. Al igual que pasó con la primera presentación de la 1812, los diarios incluyeron, previo al concierto, las descripciones que acompañan a la "Pastoral". El Tiempo Ilustrado, por su parte, presentó una sección llamada "Música cómica" en la que aparecían dibujos de las escenas de la sexta sinfonía. Lo interesante, en este caso, es que aparece una pequeña familia burguesa y un grupo de campesinos donde, "La tempestad", aparece como una riña entre los campesinos y la familia burguesa.
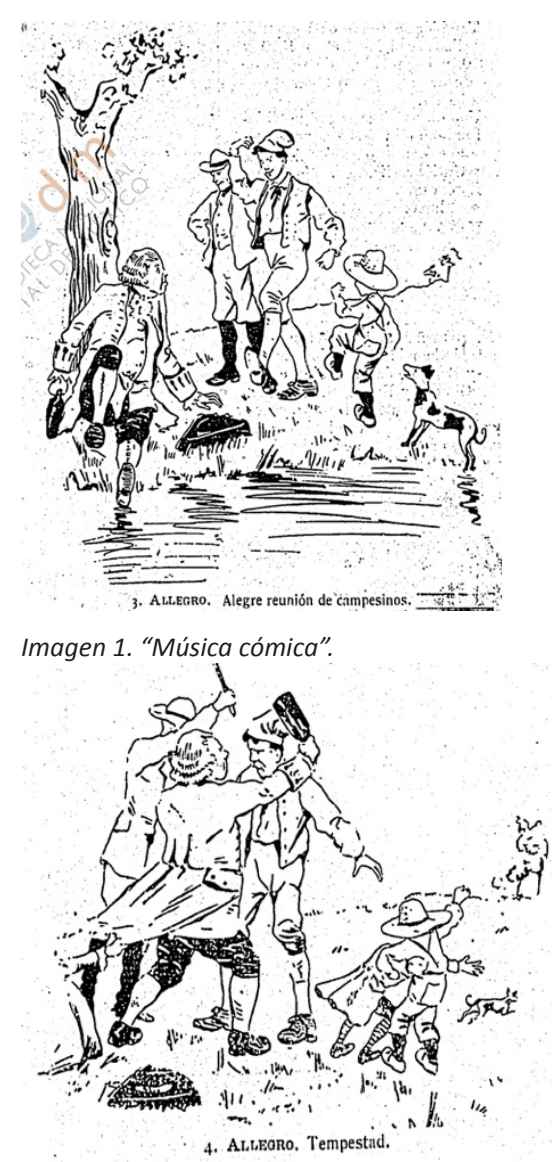

Imagen 2. "Música cómica". 


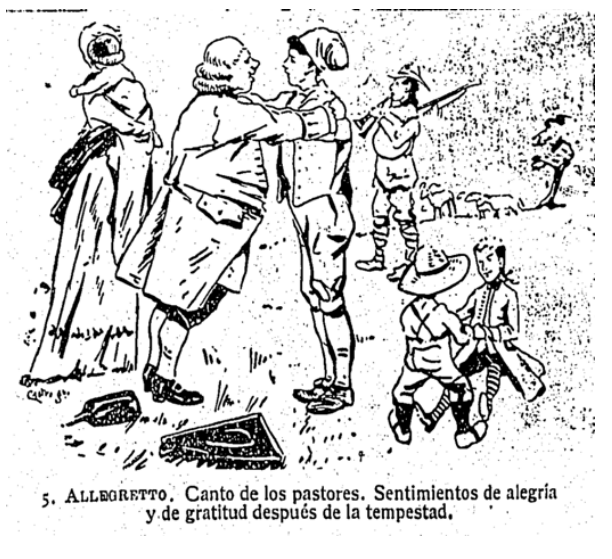

Imagen 3. "Música cómica".

El sexto abono inició con la Séptima sinfonía. Meneses repitió la Fantasía coral, el Himno a Víctor Hugo, las selecciones de la Sinfonía Patética e incluyó la cantata 5 de mayo o La muerte de Napoleón de Berlioz. Para concluir, interpretó de nuevo la Cabalgata de las Valquirias. En El Imparcial apareció la siguiente crónica:

No se han aquilatado los esfuerzos de Meneses, decía anoche en el foyer un inteligente pianista. Los méritos de las obras que se han dado en la temporada actual, las mismas que están en boga en Europa, apenas han sido comprendidas. Ya ve usted: cuántas difíciles gestiones y requisitos para importar el "Parsifal" y que bien poco el público correspondió en el concierto del domingo. Nuestro público no está preparado, replica un distinguido conocedor. De golpe y porrazo se le ofrece lo más sublime del arte, y es natural que... Pero es que hay un círculo vicioso. el público no entiende porque no va y no va porque no entiendo. Ya ve usted la aristocracia brilla por su ausencia. La clase media se toma algún interés: es la única. Íbamos a terciar. En los conciertos de tarde, las tolletes de la clase opulenta, los joyanicos de luces, el coruscar de los trajes, los matices de la seda han trocado en elegante salón la sala arcaica de San Felipe Neri: pero de noche, en invierno, la aristocracia no quiere "enfriarse"... Así perdió anoche la bellísima audición: la riquísima séptima sinfonía de Beethoven, con su primoroso "allegretto" y su "scherzo" que corre con movimiento vivo y ligero o se detiene un poco en el "sostenuto". De igual manera la elite se ha encerrado ayer en sus castillos "art nouveau" sin adivinar siquiera las sorpresas del encantamiento divino de una fantasía en que voló la imaginación de Beethoven con alas angélicas?.

La séptima presentación tuvo un cambio que puede parecer más radical pero que respondía más a una cuestión práctica. En lugar de iniciar con la Octava, repitió -por tercera vez- la Fantasía coral y la cantata 5 de Mayo. A esta le siguió Per pietá bel'idol mío de Mozart y El rey de los Alisos de Schubert. De esta forma, la segunda y tercera parte fueron para el estreno de la esperada Novena Sinfonía.

A propósito de esta obra, Maese Pedro escribió: “¡Si en la Sinfonía Heroica y en la Sinfonía Pastoral, Beethoven, por manera milagrosa, supo cantar un espléndido canto a la Naturaleza y a la Gloria, en la Novena Sinfonía, transfigurado, magnífico, enorme, cantó a la Alegría, lanzando un hondo y conmovedor grito: el grito del genio que en la cumbre se siente hermano de sus hermanos los hombres! [...]"10. Para él, esta presentación fue el hecho musical de mayor importancia hasta ese momento en México pues, la consideraba la obra más "elevada del divino arte [...] de la cual deriva toda la música moderna" 11 .

El octavo y último concierto de la temporada se dió el día 10 de noviembre y presentó un programa distinto a los anteriores. La obra de apertura fue la Octava sinfonía a la que le siguió el aria de soprano de Oberon de Weber y se repitió la Novena de Beethoven. Esto generó algunos comentarios acerca de la programación. Para el crítico de El Tiempo, al igual que para el del Mundo Ilustrado, ésta fue sin duda una ocasión histórica y de gran magnitud para la cultura en Mé-

\footnotetext{
9 "La sexta audición de la temporada "Meneses", El

Imparcial, 04 de noviembre de 1910

${ }^{10}$ Maese Pedro, "La 'Novena Sinfonía', "Teatrales", El

Mundo Ilustrado, 13 de noviembre de 1910.

${ }^{11}$ Idem
} 
xico y consideraba a Meneses como el "verdadero impulsador de la buena música", el iniciador de "una evolución en la carrera musical". Esto por lo atinado de su decisión de hacer escuchar todas las sinfonías del "genio de Bonn" ${ }^{2}$. Sin embargo, no todo fue miel sobre hojuelas. José Luis del Castillo, en su columna de El Diario señalaba el exceso en la programación. Hacía hincapié en el comentario de un amigo suyo sobre su incapacidad de soportar más de dos horas de audición musical, a otro hablar sobre el esfuerzo mental que requiere la audición de "una sola sinfonía" de Beethoven "u otra obra ardua y polifónica"13. Alguien más le señaló que en Europa nunca se programaban dos sinfonías de Beethoven juntas lo que le permite al crítico suscribir que la "Novena" debía de ir sola en el programa. La otra voz disidente, y fuerte, fue la de Alba Herrera y Ogazón. Esta ejemplar pianista y crítica, también planteó, como primer motivo de discordia, la programación. Para ella era inconcebible iniciar los conciertos con una sinfonía de Beethoven que, a su juicio, requería de un "auditorio orientado" cuya preparación debía darse a través de obras menos profundas para así, poder disfrutar a Beethoven en su totalidad. También reclama el pobre "desempeño que en general obtuvieron las sinfonías"14 debido a una aparente necesidad de finalizar pronto con la sección beethoveniana. Su crítica a la forma de dirigir de Meneses es realmente dura, tratándola de monótona y le atribuye sus faltas a no dirigir de memoria. "Volviendo al caso concreto que nos ocupa, cabe preguntar si el señor Meneses puede ser intérprete mientras esté atenido a consultar frase por frase las obras que dirige; esto es, mientras no conozca íntimamente esas obras" $" 15$.

Dentro de estas críticas, se pueden leer textos como el del mismo José Luis del

\footnotetext{
12 Zig-Zag, "El octavo concierto Meneses", El Tiempo, 11 de noviembre de 1910

${ }^{13}$ Castillo, José Luis del, "El concierto del jueves en el Arbeu", El Diario, 13/11/1910

${ }^{14}$ Herrera y Ogazón, Alba, "Los conciertos de Meneses", El Tiempo, 22/11/1910

${ }^{15}$ Ibidem
}

Castillo, quien concluye su escrito de la siguiente forma: "Y la Novena Sinfonía de melodías tan lozanas, tan nobles y tan bellas y de poliodías (sic) y modulaciones tan suntuosas, es suficiente para la deificación de Beethoven el Único, de ese hombre privilegiado que poseyó un genio tan poderoso y una imaginación tan feraz, ¡como la Naturaleza!”16.

\section{A manera de conclusión}

Indudablemente, la figura de Ludwig van Beethoven, es un referente occidental para la música del mundo. La programación de sus sinfonías, particularmente la Tercera, la Quinta o la Novena, sin importar cuando y donde se presenten, son un éxito seguro.

En el caso que nos ocupa, el México de principios del siglo XX, la expectación provocada por las obras sinfónicas del "sordo de Bonn" y en particular de la Novena, puede leerse en los diarios de la época. Las columnas de espectáculos y las de sociales, dan cuenta de la forma como va acrecentándose la participación del público. La crítica a las obras es siempre favorable. Se reconoce - de antemano - la factura de las obras y su capacidad para mejorar el ambiente musical de México. En estas notas se expone tanto lo que se habrá de escuchar como la presentación en sí misma. La imagen decimonónica del "Cisne de Bonn" es repetida en nuestros diarios. En ellas se ve tanto la representación musical de la vida del genio, como la vida atormentada de un pequeño gigante que supo sobreponerse a las penurias gracias a sus dones, así como la fortaleza que se requiere para sobrepasar las limitaciones humanas y, que con su música, logró transformar al arte.

\footnotetext{
${ }^{16}$ Castillo, José Luis del, "El concierto del jueves en el Arbeu", El Diario, 13/11/1910
} 